\title{
Catalysts supported on polymer colloids
}

\author{
Warren T. Ford, ${ }^{*}$ Rama Chandran, and Hayrettin Turk \\ Department of Chemistry, Oklahoma State University, \\ Stillwater, Oklahoma 74078, U.S.A.
}

\begin{abstract}
Polymer colloids containing tetraalkylphosphonium ions as phase transfer catalysts and cobalt ions as autoxidation catalysts have been prepared by emulsion polymerization and subsequent functional group transformations on the colloids. The $0.27 \mu \mathrm{m}$ colloidal phase transfer catalysts are more active for reaction of cyanide ion with benzyl bromide than are the analogous $20 \mu \mathrm{m}$ spherical bead catalysts, but the high electrolyte strengths used in phase transfer catalysis cause the colloids to coagulate. Cobalt phthalocyanine tetrasulfonate bound to ion exchange colloids catalyzes autoxidation of 2,6-di-t-butylphenol. Cobalt ions bound as carboxylic acid salts to poly(acrylic acid) and poly(methacrylic acid) copolymer latexes in the presence of amine ligands catalyze autoxidation of tetralin.
\end{abstract}

\section{INTRODUCTION}

Catalysis is essential for many chemical reactions, from enzymatic processes in living organisms to industrial production of commodity chemicals. Catalysts may be homogeneous or heterogeneous. They may have simple chemical structures such as acids or bases, they may have intricate chemical structures such as certain transition metal complexes, or they may occur in nature as enzymes so complex that chemists have not yet been able to duplicate their performance. High activity and chemical selectivity are the properties most desired in a catalyst, but often those goals must be tempered by practical considerations of cost and ease of use.

Many polymer-supported catalysts have been prepared (refs. 1-2). Macroscopic polymer particles can be recovered from reaction mixtures and recycled if they have not degraded chemically or physically. They can be used in flow reactors. Most polymer-supported catalysts have been designed as immobilized analogues of successful homogeneous catalysts. Cross-linked poly(styrenesulfonic acid) is an insoluble analogue of $p$-toluenesulfonic acid. Optically active bis-phosphine complexes supported on insoluble polymers are catalysts for asymmetric hydrogenation of $\mathrm{N}$-acylamino acids analogous to those used for the industrial synthesis of the amino acid L-Dopa (ref. 3). Sometimes polymer-supported catalysts have had activities greater than those of the soluble analogues, but most often they are less active because of diffusional limitations inherent to heterogeneous catalysis.

Our initial investigations of polymer colloids as catalyst supports are described here. A colloid is a dispersion of particles that are generally less than one $\mu \mathrm{m}$ in diameter. In a liquid they remain dispersed by Brownian motion. They may be either charge-stabilized or sterically-stabilized. Steric stabilization means that the particle surface is coated with adsorbed polymers that repel one another when the polymer random coils from two particles interpenetrate (ref. 4). Colloids have high surface to volume ratios, which should be advantageous for heterogeneous catalysts.

Surfactant micelles and microemulsions are other types of colloids that have been investigated as sites for catalysis (ref. 5). Often the goal has been to mimic enzymes. More recently attention has focused on bilayer membrane vesicles as loci for catalysis. Vesicles are structurally similar to the simplest phospholipid bilayer membranes found in nature. To overcome the poor stability of synthetic vesicles numerous methods have been devised to polymerize the surfactants, and considerably greater bilayer stability has been achieved (refs. 6-10).

In emulsion polymerization a dispersion of surfactant micelles and monomer droplets in water is polymerized with a free radical initiator (refs. 11-12). Micelles containing monomer grow into polymer particles $0.05-0.5 \mu \mathrm{m}$ in diameter, while the monomer droplets disappear by transport of their contents through the water to the growing polymer particles. Emulsion polymerization has been widely used for the preparation of polymer and copolymer latexes of styrene, butadiene, vinyl acetate, vinyl chloride, and acrylic and methacrylic esters. We have adopted it for the preparation of colloidal copolymers bearing functional groups that can be transformed into catalyst sites.

A few synthetic colloidal catalysts have been reported. Semiconductors such as titanium dioxide and cadmium sulfide, as $<0.1 \mu \mathrm{m}$ particles stabilized by adsorbed hydrophilic polymers, have been studied as photocatalysts (refs. 13-14). Colloidal ferric oxide, zinc oxide, and titanium dioxide have been used for photocatalytic reduction of oxygen (ref. 15). Metal particles have been generated in microemulsions and in polymerized surfactant vesicles and tested as catalysts for hydrogenation and 
hydrosilation (refs. 16-23). Colloidal polymeric sulfonic acids (ref. 24) and imidazoles (refs. 25-27) have been used as catalysts for hydrolyses. Poly(sodium acrylate) and poly(sodium styrenesulfonate) latexes have been compared with soluble polyelectrolytes as "catalysts" (rates were retarded) for reaction of $\mathrm{Co}\left(\mathrm{NH}_{3}\right)_{5} \mathrm{Br}^{+2}$ with hydroxide ion (ref. 28). Enzymes have been immobilized on polymer latexes (ref. 29).

\section{COLLOIDAL PHASE TRANSFER CATALYSTS}

Kinetic investigations of catalysis of displacements on water-insoluble alkyl halides by water-soluble inorganic salts catalyzed by insoluble polymer-supported quaternary ammonium and phosphonium ions, crown ethers, and poly(ethylene glycol)s have shown that rapid reactions are retarded by mass transport steps (ref. 30). For example, the rate of reaction of sodium cyanide with 1-bromooctane (eq. 1) catalyzed by polystyrene-bound tetraalkylphosphonium ions (1) is limited by mass transfer of one or both reactants to the catalyst particle surface if agitation of the triphase reaction mixture is not vigorous enough (refs. 31-32). Even with vigorous agitation the reactants must still diffuse from the particle surface to the active sites within. The dependence of observed reaction rates on catalyst particle sizes as small as $20 \mu \mathrm{m}$ diameter and on the degree of divinylbenzene-cross-linking of the polymer in the range 2-10\% DVB indicates intraparticle diffusional limitations. Smaller catalyst particles have greater surface area and shorter diffusion paths to the active sites per unit weight of catalyst. Higher polymer cross-linking creates a more tortuous diffusion path for reactants to reach the active sites and restricts swelling to give a less fluid polymer gel. Diffusional limitations are greatest when the inherent reactivity is highest. Slow reactions with half-lives of many hours proceed with rates independent of agitation and catalyst particle size.

$$
n-\mathrm{C}_{8} \mathrm{H}_{17} \mathrm{Br}+\mathrm{NaCN}(\mathrm{aq}) \longrightarrow n-\mathrm{C}_{8} \mathrm{H}_{17} \mathrm{CN}+\mathrm{NaBr}(\mathrm{aq})
$$

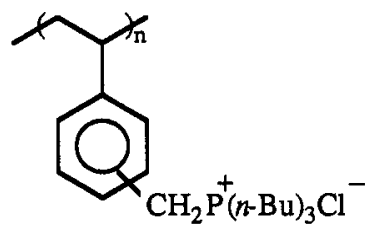

1

Since phase transfer catalysts on even the smallest polystyrene supports prepared by suspension polymerization apparently had not achieved rates for nucleophilic displacements as high as rates with soluble catalysts, particles two orders of magnitude smaller were prepared via emulsion copolymerization of chloromethylstyrenes, styrene, and divinylbenzene (eq. 2) (ref. 33). Hexadecyltrimethylammonium bromide and azobis(isobutyronitrile) served as surfactant and initiator for the emulsion polymerizations, which gave $0.08-0.3 \mu \mathrm{m}$ diameter latex particles. The chloromethyl groups were converted to phosphonium salts 1 by refluxing the emulsions with tri- $n$ butylphosphine. The colloidal catalysts contained $10-20 \%$ by weight of particles and $0.89-1.04$ mequiv of $P$ per $g$ of dry latex.<smiles>C=Cc1ccc(CCl)cc1</smiles>

\section{styrene}

divinylbenzene

copolymerize

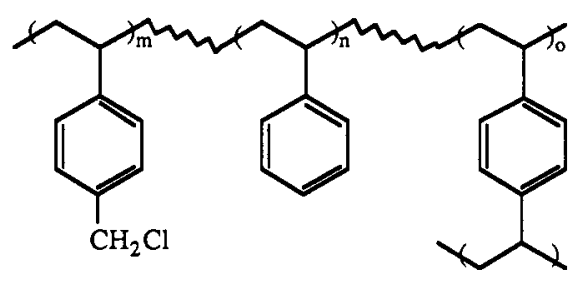

All attempts to catalyze the reaction of 1-bromooctane in toluene with concentrated aqueous sodium cyanide (eq. 1) with the colloidal catalysts resulted in fast coagulation of the particles. This is not surprising because electrolytes cause coagulation of charged colloids by screening the electrostatic repulsions. Independently the critical concentrations of sodium cyanide required to precipitate a $10 \%$ solids phosphonium ion latex 1 were determined to be $0.2 \mathrm{M}$ at $25^{\circ} \mathrm{C}$ and $0.1 \mathrm{M}$ at $80^{\circ} \mathrm{C}$. Coagulated, $2 \%$ cross-linked particles were sieved into a 10-37 $\mu \mathrm{m}$ fraction, which was tested as a catalyst in comparison with a $2 \%$ cross-linked bead catalyst of the same size and a soluble polystyrene-supported catalyst with the same degree of functionalization $(1.0$ mequiv/g). The results in Table 1 indicate highest activity for the soluble catalyst.

Catalysis without coagulation of the polystyrene-bound, phosphonium ion colloids was achieved for the reaction of sodium cyanide with benzyl bromide (eq. 3) if the colloidal catalyst was conditioned in benzyl bromide before addition of toluene or aqueous sodium cyanide. When the reagents and solvent were added in that order, activity of the latex catalyst was four times greater than that of the previously most active $10-37 \mu \mathrm{m}$ spherical bead catalyst of the same composition (Table 2 ). Coagulation did occur slowly, but rates of reactions with half lives of four minutes could be determined first. Combining the reagents and solvents in every other possible order coagulated the colloid immediately. We speculate that benzyl bromide retards coagulation because it is such a good 
Table 1. Reaction Rate Constants for Cyanide Ion with 1-Bromooctane ${ }^{a}$

\begin{tabular}{ll}
\hline catalyst & $10^{5} \mathrm{k}_{\text {obsd, }} \mathrm{s}^{-1}$ \\
\hline $10-37 \mu \mathrm{m}$ spherical beads & 38 \\
$10-37 \mu \mathrm{m}$ coagulated latex & 31 \\
soluble polymer & 53.4 \\
\hline
\end{tabular}

aFrom ref. 33. $90^{\circ} \mathrm{C}, 600 \mathrm{rpm}$ mechanical stiring of $0.464 \mathrm{mmol}$ of catalyst with $20 \mathrm{~mL}$ of toluene, $20 \mathrm{mmol}$ of 1-bromooctane, $30 \mathrm{~mL}$ of water, and $9.8 \mathrm{~g}$ of $\mathrm{NaCN}$.
Table 2. Rates of Reaction of Benzyl Bromide with Cyanide Ion ${ }^{2}$

\begin{tabular}{lcr}
\hline particle size, $\mu \mathrm{m}$ & $\%$ DVB & $10^{5} \mathrm{k}_{\text {obsd }}, \mathrm{s}^{-1}$ \\
\hline $10-37$, spherical beads & 2 & 510 \\
0.27 & 2 & 2200 \\
0.116 & 10 & 1120 \\
$n-\mathrm{Bu}_{3} \mathrm{~Pb}^{\mathrm{b}}$ & & 51 \\
$n-\mathrm{C}_{16} \mathrm{H}_{33} \mathrm{~N}^{+} \mathrm{Me}_{3} \mathrm{Br}^{-\mathrm{c}}$ & & 74 \\
\hline
\end{tabular}

aFrom ref. $33.80^{\circ} \mathrm{C} ; 0.33 \mathrm{mmol}$ of catalyst in $10 \mathrm{~mL}$ of water $23 \mathrm{mmol}$ of benzyl bromide, $10 \mathrm{~mL}$ of toluene, and $20 \mathrm{~mL}$ of water containing $5.0 \mathrm{~g}$ of $\mathrm{NaCN}$ were mixed in that order.

b $0.35 \mathrm{~mol} \%$ based on benzyl bromide.

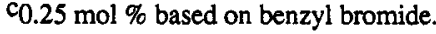

solvent for the catalyst that polymer chains extend farther out from the cross-linked core of the particles, providing limited steric stabilization of the colloid. We suspected that the greater activity of the colloidal catalysts might be due to the presence of residual surfactant, hexadecyltrimethylammonium bromide, remaining from the emulsion polymerization, or to soluble benzyltri- $n$-butylphosphonium ion, formed from tri- $n$-butylphosphine remaining from the preparation of the catalyst. However, deliberate addition of tri- $n$-butylphosphine or of hexadecyltrimethylammonium bromide to reaction mixtures containing no polymeric catalyst gave reaction rates less than $4 \%$ as fast as that attained with the most active colloidal catalyst.

$$
\mathrm{C}_{6} \mathrm{H}_{5} \mathrm{CH}_{2} \mathrm{Br}+\mathrm{NaCN}(\mathrm{aq}) \longrightarrow \mathrm{C}_{6} \mathrm{H}_{5} \mathrm{CH}_{2} \mathrm{CN}+\mathrm{NaBr}(\mathrm{aq})
$$

The catalysis of the reaction of benzyl bromide with cyanide ion demonstrates that the small size of colloidal catalyst particles can give higher activity, but the difficulties with coagulation of charged colloids by electrolytes and by many organic solvents make them impractical phase-transfer-catalysts. Consequently we have turned our attention to reactions that can be carried out in aqueous colloids with low concentrations of organic reactants and no added electrolytes.

\section{COBALT-CATALYZED AUTOXIDATIONS}

Polymer colloids (latexes) have been prepared with ionic functional groups for electrostatic binding of metal ion catalysts, as in ion exchange resins. Binding of both cationic and anionic cobalt(II) species has been achieved. Cobalt is the most generally active metal for autoxidation of organic compounds (ref. 34). All of the latexes contain divinylbenzene as a cross-linker to prevent dissolution of the polymer at any time during preparation or use. Without the cross-linking monomer, the product latexes first formed would be soluble in some organic solvents, and the ionic latexes used as catalysts might be soluble as polyelectrolytes in water.

Emulsion polymerization of mixtures of chloromethylstyrene, styrene and divinylbenzene in various proportions gave latexes (eq. 2) (refs. 35-37) described in Table 3. Both sodium dodecyl sulfate and hexadecyltrimethylammonium bromide were used as emulsifiers to provide latexes stabilized by anionic and cationic surface charge. Treatment of the latexes with trimethylamine converted most of the chloromethyl groups to quaternary ammonium chlorides (2). The mols of cationic sites created always exceeded the mols of surfactant used in the polymerization, so latexes 2 were always stabilized by positive net surface charge. Divinylbenzene contents of $1 \%$ and $5 \%$ gave latexes capable of great

Table 3. Ion Exchange Latexes

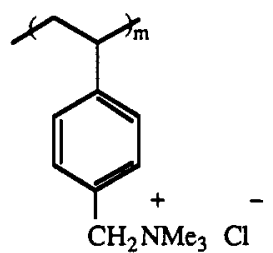

2

\begin{tabular}{lcccc}
\hline $\begin{array}{c}\text { copolymer } \\
\text { composition }\end{array}$ & surfactant & $\begin{array}{c}\text { wt \% solids } \\
\text { in water }\end{array}$ & $\begin{array}{c}\text { DF, } \\
\mathrm{N}^{+} \mathrm{Cl}^{-}\end{array}$ & $\begin{array}{c}\text { maximum } \\
\text { N/Cod }\end{array}$ \\
\hline $91.2 \mathrm{VBC}, 4.9 \mathrm{DVB}$ & SDS & solide & 0.61 & 3.74 \\
$98.2 \mathrm{VBC}, 1.0 \mathrm{DVB}$ & SDS & 4.6 & 0.87 & 4.35 \\
$91.3 \mathrm{VBC}, 4.8 \mathrm{DVB}$ & CTAB & 9.4 & 0.81 & 4.59 \\
$98.2 \mathrm{VBC}, 1.0 \mathrm{DVB}$ & CTAB & 4.8 & 0.85 & - \\
$18.9 \mathrm{VBC}, 1.0 \mathrm{DVB}$ & CTAB & 8.4 & 0.21 & - \\
\hline
\end{tabular}

\footnotetext{
a Mol \% of original latex. VBC is vinylbenzyl chloride. DVB is divinylbenzene. bSDS = sodium dodecyl sulfate; CTAB = hexadecyltrimethylammonium bromide. ${ }^{C}$ Degree of functionalization, the fraction of polystyrene rings substituted with quaternary ammonium groups.

$\mathrm{d}$ Maximum ammonium ion to cobalt ratio achieved in latex with no observable CoPcTs in water.

eCharacterizations were performed on coagulated particles.
} 
and moderate swelling respectively in good solvents for the polymers. Chloromethylstyrene contents of $19 \%$ and $91-98 \%$ in the copolymers led to greatly varied charge densities of the ion exchange latexes 2 . Ion exchange capacities of 2 were determined by analysis of the chloride ion content of each latex. All of the polymers in Table 3 are stable colloids. However, others not reported here have coagulated.

Cobalt(II) phthalocyanine tetrasulfonate (CoPcTs) (3) was chosen as a catalyst because it promised to provide rapid electron transfer reactions and limit formation of less catalytically active oxygen bridged Co dimers. The ability of silica gel and polystyrene supports to prevent oxidative dimerization of $\mathrm{Fe}$ (II) porphyrin to $\mathrm{Fe}$ (III)-O-Fe(III) is well known (ref. 38). The phthalocyanine ring system is more stable to redox reactions than the porphyrins and tetraarylporphyrins more commonly used in catalytic oxidation studies (ref. 39 ). CoPcTs has been bound to polystyrene beads (refs. 40-44), to cross-linked polyacrylamide (refs. 45-46), and to soluble and cross-linked poly(vinylamine) (refs. 47-52).

Each ion exchange latex 2 was exposed to various amounts of cobalt(II)phthalocyanine tetra(sodium sulfonate). The intensely blue phthalocyanine can be detected in solution by human eye to concentrations lower than $10^{-7} \mathrm{M}$. Ultrafiltration of the latex through a $0.1 \mu \mathrm{m}$ membrane gave colorless filtrate and retained blue latex from each sample as long as no more than approximately one CoPcTs was added per four ammonium ion sites in the latex. In each example in Table 3, addition of the next increment of CoPcTs to the latex resulted in a light blue filtrate. With no detectable CoPcTs in the external water we can be confident that the active catalytic sites in subsequent oxidation processes are latex-bound CoPcTs.

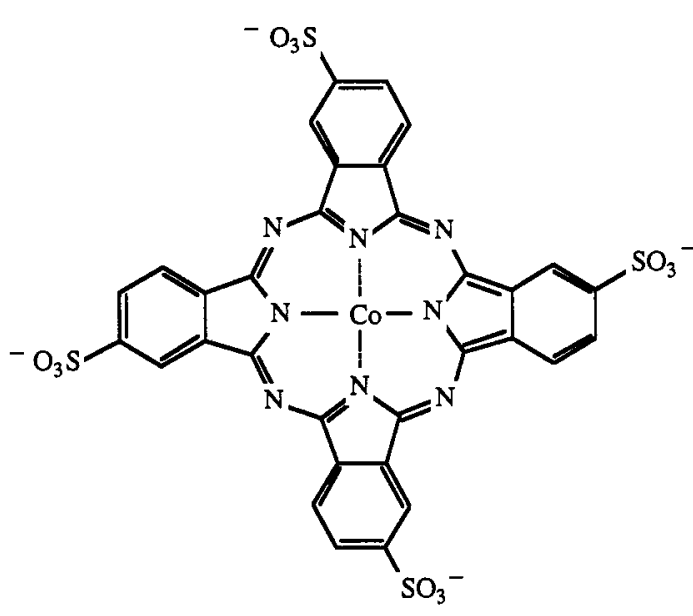

3 CoPcTs<smiles>CC(C)(C)C1=CC(=C2C=C(C(C)(C)C)C(=O)C(C(C)(C)C)=C2)C(C(C)(C)C)=CC1=O</smiles>

Autoxidation of 2,6-di-t-butylphenol under one atmosphere of oxygen at $70^{\circ} \mathrm{C}$ with both soluble and latex-bound CoPcTs catalysts in water produced 2,6-di-t-butylbenzoquinone and 2,6,2',6'-tetra-tbutyldiphenoquinone (eq. 4) (refs. 53-54). Oxygen consumption was followed with a gas burette Preliminary results are $66 \%$ consumption of $0.25 \mathrm{~g}$ of di-t-butylphenol in $150 \mathrm{~mL}$ of $10 / 1 \mathrm{v} / \mathrm{v}$ water/methanol with $0.06 \mathrm{mmol}$ of soluble CoPcTs in $24 \mathrm{~h}$, and $100 \%$ consumption under the same conditions with a CoPcTs catalyst bound to the first latex listed in Table 3 . There is a large rate enhancement with the latex catalyst compared to its soluble analogue, but no kinetics have been investigated yet.

A second group of stable copolymer latexes was prepared from styrene and methacrylic acid (10 and 20 mol percent), and styrene and acrylic acid ( 20 and 76 mol percent) by emulsion polymerization with $1 \%$ divinylbenzene as cross-linker and sodium dodecyl sulfate as surfactant. Available acid sites in the latexes were determined by conductometric titration to be about $15 \%$ less than the stoichiometric amounts. Conversion of most latex acid sites to the potassium salts, followed by addition of $\mathrm{CoCl}_{2}$, resulted in conversion of up to $85 \%$ of the acid sites to pink $\mathrm{Co}$ (II) salts (eq. 5 ). $\mathrm{More}^{\mathrm{CoCl}}$ precipitated the pink latex, as expected from treatment of an anionic colloid with excess divalent metal ion salt. An upper limit of $10^{-4} \mathrm{M} \mathrm{Co}$ (II) in the aqueous phase was determined for one latex sample prepared using 0.25 molar equivalent of $\mathrm{CoCl}_{2}$. The aqueous phase was separated from the colloidal particles for analysis by ultrafiltration through a $0.1 \mu \mathrm{m}$ cellulose acetate/nitrate membrane. The $\mathrm{Co}$ (II) latexes were purified by ultrafiltration until the conductivity of the filtrate reached a constant value of about $20 \mathrm{ohm}^{-1} \mathrm{~cm}^{-1}$. Enhanced optical microscopy of the latexes before Co(II) incorporation showed particle diameters of $<0.5 \mu \mathrm{m}$ by comparison with standard monodisperse polystyrene latexes. 


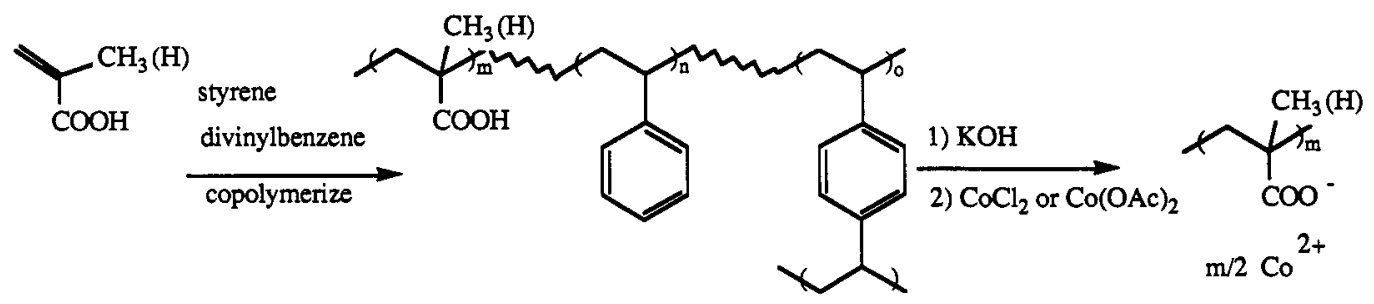

Tetralin was chosen as a model alkylbenzene substrate for cobalt-catalyzed hydrocarbon autoxidations because it gives easily analyzed product mixtures of tetrol and tetralone (eq. 6) (ref. 55). Soluble $\mathrm{Co}(\mathrm{OAc})_{2} \cdot 6 \mathrm{H}_{2} \mathrm{O}$ was chosen as catalyst for preliminary oxidation experiments. The autoxidation of tetralin proceeded to $60 \%$ conversion in $60 \mathrm{~h}$ at $50{ }^{\circ} \mathrm{C}$ in acetic acid, but there was no reaction at all in water. The oxidation potential for conversion of $\mathrm{Co}$ (II) to $\mathrm{Co}$ (III) is $1.84 \mathrm{~V}$ in water, but for conversion of $\left[\mathrm{Co}\left(\mathrm{NH}_{3}\right)_{6}\right]^{+2}$ to $\left[\mathrm{Co}\left(\mathrm{NH}_{3}\right)_{6}\right]^{+3}$ is only $0.1 \mathrm{~V}$ (ref. 56). Since the binding of dioxygen to $\mathrm{Co}$ (II) to give $\mathrm{Co}$ (III) is likely a key step in the catalytic autoxidation mechanism, stronger ligands appeared to be needed for the $\mathrm{Co}$ (II) to act as a catalyst. Addition of aqueous ammonia to the aqueous Co(II) solution gave a catalyst more active for tetralin autoxidation in water than $\mathrm{Co}(\mathrm{OAc})_{2}$ was in acetic acid. Pyridine as a ligand for $\mathrm{Co}$ (II) gave still faster autoxidations. More strongly coordinating and chelating ligands such as 1-methylimidazole, 2,2'-bipyridine, 1,10phenanthroline, and 2-picolinic acid gave slower reactions. Co(II) ligated with linear poly(4vinylpyridine) in a $\mathrm{pH} 7-8$ aqueous suspension was slightly active when the reaction mixture was mixed with magnetic stirring, and more active with agitation by an ultrasonic bath.

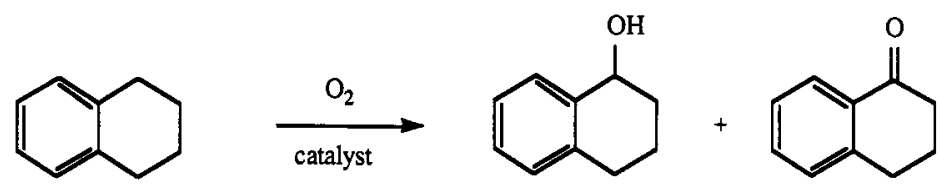

The aim of the ligand studies with soluble Co catalysts for tetralin autoxidation is to determine what ligands in latex catalysts should lead to the most active catalysts. Latexes have been prepared containing varied amounts of $\mathrm{Co}(\mathrm{II})$ as shown in Table 4 . Preliminary autoxidations of tetralin reported in Table 4 show that the latex catalysts are more active than cobalt acetate in acetic acid and about as active as $\mathrm{Co}$ (II) in water in the presence of six mols of pyridine per cobalt ion.

Table 4. Autoxidation of Tetralin with Co(II) Catalysts Bound to Latexes ${ }^{a}$

\begin{tabular}{|c|c|c|c|c|c|}
\hline \multicolumn{4}{|c|}{ compositions of colloidal catalysts } & \multicolumn{2}{|c|}{ oxidation reactions } \\
\hline $\begin{array}{l}\text { copolymer } \\
\text { composition }^{b}\end{array}$ & $\begin{array}{l}\%-\mathrm{COOH} \\
\text { in Co-form }\end{array}$ & $\begin{array}{l}\mathrm{Co}(\mathrm{II}) \\
\text { mequiv } \mathrm{g}^{-1}\end{array}$ & $\begin{array}{c}\% \\
\text { solids }\end{array}$ & $\begin{array}{c}\mathrm{Co}(\mathrm{II}) \\
\mathrm{mM}\end{array}$ & $\begin{array}{c}\% \text { tetralin } \\
\text { oxidized }\end{array}$ \\
\hline \multirow[t]{2}{*}{$\begin{array}{l}20 \% \text { AA } \\
20 \% \text { AA } \\
76.7 \% \text { AA } \\
20 \% \text { MAA }\end{array}$} & $\begin{array}{c}5.8 \\
5.8 \\
95 \\
5.1\end{array}$ & $\begin{array}{l}0.12 \\
0.12 \\
4.0 \\
0.11\end{array}$ & $\begin{array}{l}1.1 \\
1.1 \\
0.8 \\
2.2\end{array}$ & $\begin{array}{l}1.6 \\
4.1 \\
1.6 \\
1.6\end{array}$ & $\begin{array}{l}60 \\
67 \\
52 \\
62\end{array}$ \\
\hline & \multicolumn{3}{|c|}{ soluble poly(4-vinylpyridine $)^{c}$} & 1.3 & 62 \\
\hline
\end{tabular}

aAll oxidations were performed for $48 \mathrm{~h}$ at $50^{\circ} \mathrm{C}$ with $0.13 \mathrm{M}$ tetralin in water and six mols of pyridine per cobalt.

$\mathrm{b}_{\mathrm{AA}}=$ acrylic acid; MAA = methacrylic acid. Latexes contained AA or MAA and $1 \mathrm{~mol}$ $\%$ divinylbenzene, and the rest was styrene.

CReaction mixture was held in an ultrasonic bath.

\section{CONCLUSIONS}

Polymer colloids can be modified with catalytic groups just as macroscopic polymer particles can. Exposure to aqueous electrolytes and sometimes to organic solvents can cause the colloids to coagulate, but often they can be redispersed. Coagulation and filtration can be used to separate catalysts from aqueous reaction mixtures if necessary. Colloidal cobalt catalysts show promise of high activity for autoxidations of organic compounds in water.

Acknowledgements We thank the U. S. Environmental Protection Agency for grant R812198-01-0 and the U. S. Army Research Office for contracts DAAG29-82-K0133 and DAAL 03-86-K-0049 in support of this research. 


\section{REFERENCES}

1. P. Hodge and D. C. Sherrington, Eds. "Polymer-supported Reactions in Organic Synthesis," Wiley, Chichester, 1980.

2. W. T. Ford, Ed. "Polymeric Reagents and Catalysts," Am. Chem. Soc. Symp. Ser. vol 308, 1986.

3. R. Deschenaux and J. K. Stille, J. Org. Chem., 50, 2299 (1985), and references therein.

4. R. H. Ottewill in "Emulsion Polymerization," I. Piirma, Ed. New York, Academic Press, 1982, pp. 1-49 and references therein.

5. J.H. Fendler, "Membrane Mimetic Chemistry," Wiley-Interscience, New York, 1982.

6. H. Bader, K. I. Dorn, B. Hupfer and H. Ringsdorf, Adv. Polym. Sci., 64, 1 (1985).

7. J. H. Fendler and P. Tundo, Acc. Chem. Res. 14, 45 (1985).

8. J. A. Hayward, D. S. Johnston and D. Chapman, Ann. N. Y. Acad. Sci., 446, 267 (1985).

9. D. F. O'Brien, R. T. Klingbiel, D. P. Specht and P. N. Tyminski, Ann. N. Y. Acad. Sci., 446, 282 (1985).

10. A. Sadownik, J. Stefely and S. L. Regen, J. Am. Chem. Soc., 108, 7789 (1986).

11. D. C. Blackley, "Emulsion Polymerization," Wiley, New York, 1975.

12. I. Piirma, Ed. "Emulsion Polymerization," Academic Press, 1982.

13. T. Nakahira and M. Gratzel, J. Phys. Chem., 88, 4006 (1984), and references therein.

14. Y.-M. Tricot and J. H. Fendler, J. Am. Chem. Soc., 106, 2475 (1984).

15. D. W. Bahneman, J. Kern, C. Kormann and M. R. Hoffmann, American Chemical Society 192nd National Meeting, Sept. 1986; Abstract COLL 22.

16. K. Kurihara and J. H. Fendler, J. Am. Chem. Soc., 105, 6152 (1983).

17. J. H. Fendler, Science, 223, 888 (1984).

18. M. Boutonnet, J. Kizling, P. Stenius and G. Maire, Colloids and Surfaces, 5, 209 (1982).

19. H. Hirai, H. Wakabayashi and M. Komiyama, Makromol. Chem., Rapid Commun., 5, 381 (1984).

20. H. Hirai, Makromol. Chem., Suppl., 14, 55 (1985).

21. H. Hirai, H. Chawanya and N. Toshima, React. Polym., 3, 127 (1985).

22. H. Hirai, M. Ohtaki and M. Komiyama, American Chemical Society 192 nd National Meeting, Sept. 1986, Abstract COLL 23.

23. L. N. Lewis and N. Lewis, J. Am. Chem. Soc., 108, 7228 (1986).

24. R. M. Fitch, in "Macromolecules," H. Benoit and P. Rempp, Eds., Pergamon Press, Oxford, 1982, p. 39.

25. A. Hopkins and A. Williams, J. Chem. Soc., Perkin Trans. II, 891 (1983).

26. H. Kitano, Z.-H. Sun and N. Ise, Macromolecules, 16, 1306 (1983).

27. Z. Sun, C. Yan and H. Kitano, Macromolecules, 19, 984 (1986).

28. T. Ishiwatari, T. Maruno, M. Okubo, T. Okubo and N. Ise, J. Phys. Chem., 85, 47 (1981).

29. H. Kitano, K. Nakamura and N. Ise, J. Appl. Biochem., 4, 34 (1982).

30. W. T. Ford and M. Tomoi, Adv. Polym. Sci., 55, 49 (1984).

31. M. Tomoi and W. T. Ford, J. Am. Chem. Soc., 102, 7140 (1980).

32. M. Tomoi and W. T. Ford, J. Am. Chem. Soc., 103, 3821 (1981).

33. M. Bernard, W. T. Ford and T. W. Taylor, Macromolecules, 17, 1812 (1984).

34. R. A. Sheldon and J. K. Kochi, "Metal-Catalyzed Oxidations of Organic Compounds," Academic Press, New York, 1980, Chapters 4 and 5.

35. B. P. Chong, E. G. Isacoff and J. W. Neely, U. S. 4,200,695 (1980),

36. G. A. Campbell and D. A. Upson, Macromol. Syn., in press.

37. R. A. Wessling, in "Science and Technology of Polymer Colloids," Vol. II, G. W. Poehlein, R. H. Ottewill and J. W. Goodwin, Eds., Martinus Nijhoff Publishers, The Hague, 1983, p. 393.

38. O. Leal, D. L. Anderson, R. G. Bowman, F. Basolo and R. L. Burwell, Jr., J. Am. Chem. Soc., 97,5125 (1975).

39. F. H. Moser and A. L. Thomas, "The Phthalocyanines," Vols. I and II, CRC Press, Inc., Boca Raton, FL, 1983.

40. H. Ledon and Y. Brigandat, J. Organomet. Chem., 165, C25 (1979).

41. L. Rollmann, J. Am. Chem. Soc., 97, 2132 (1975).

42. A. Skorobogaty and T. D. Smith, J. Mol. Catal., 16, 131 (1982).

43. H. Shirai, A. Maruyama, K. Kobayashi, N. Hojo and K. Urushido, J. Polym. Sci., Polym. Lett. Ed., 17, 661 (1979).

44. H. Shirai, S. Higaki, K. Hanabusa, Y. Kondo and N. Hojo, J. Polym. Sci., Polym. Chem. Ed., 22, 1309 (1984).

45. T. A. M. M. Maas, M. Kuijer and J. Zwart, J. Chem. Soc., Chem. Commun., 86 (1976).

46. J. H. Schutten and J. Zwart, J. Mol. Catal., 5, 109 (1979),

47. W. M. Brouwer, P. Piet and A. L. German, Polymer Commun., 24, 216 (1983).

48. W. M. Brouwer, P. Piet and A. L. German, Polym. Bull., 8, 245 (1982).

49. W. M. Brouwer, P. Piet and A. L. German, J. Mol. Catal., 22, 297 (1984).

50. W. M. Brouwer, P. Piet and A. L. German, Makromol. Chem., 185, 363 (1984).

51. W. M. Brouwer, P. Piet and A. L. German, J. Mol. Catal., 31, 169 (1985).

52. W. M. Brouwer, P. Piet and A. L. German, J. Mol. Catal., 29, 335 (1985).

53. V. M. Kothari and J. J. Tazuma J. Catal., 41, 180 (1976).

54. A. Zombeck, R. S. Drago, B. B. Corden and J. H. Gaul. J. Am. Chem. Soc., 103, 7580 (1981).

55. Y. Kamiya, S. Beaton, A. Lafortune and K. U. Ingold, Can. J. Chem., 41, 2020, 2034 (1963).

56. F. A. Cotton and G. Wilkinson,"Advanced Inorganic Chemistry," 2nd edn., 1966, WileyInterscience, New York, pp. 863-878. 